\title{
Demanding business travel: the evolution of the timespaces of business practice
}

\author{
Ian Jones*, Jillian Annable*, James Faulconbridge**, Greg Marsden* \\ * Institute for Transport Studies, Leeds University \\ ** Lancaster University
}

\begin{abstract}
To date, virtual ways of working have yet to substantially reduce demand for business travel. Emerging research claims that virtual and physical work compliment rather than substitute for one another. This suggests travel demand stems from business strategies and achieving business outcomes. In building on these ideas, this chapter draws upon Schatzki's conception of timespace to capture changes in how two UK-based global construction and engineering consulting firms organise work and the implications in terms of demand for business travel. Overtime, particular forms of spatially stretched organisation which have developed are found to require the interweaving of timespaces through travel. As such, how each firm has evolved has in turn created the contemporary situation of significant and hard to reduce demand for travel.
\end{abstract}

\section{Introduction}

Compare walking down the hallway to collect a report from a printer on the way to a client meeting in an office in the same city with collecting the report on the way home as part of a larger set of activities to prepare for an international flight to meet a client in a different country. The energy demand of the former is a number of magnitudes less than the latter. Further, in addition to environmental implications (Lassen, 2010; Urry, 2012), differences in travel that arise from the two examples also have important implications for the wellbeing of 
workers (Gustafson, 2006, 2012), and corporate finances (World Travel and Tourism Council, 2011). Yet, despite these effects, there continues to be a growing tendency for the doing of business to involve travel, very often international. How do we explain this?

As part of the mobilities turn (Sheller and Urry, 2006), significant effort has been made to analyse the relationships between the globalisation of professional services (such as accounting, advertising, architecture, engineering and law) and 'portfolios' of business mobility which produce an internationally hyper-mobile class of workers (Faulconbridge et al., 2009; Millar and Salt, 2008; Salt and Wood, 2012). To date, the majority of the business travel literature has focussed on charting types of travel and the face-to-face contact it allows (e.g., Davidson and Cope, 2003; Faulconbridge et al., 2009; Jones, 2007; Lyons, 2013; Millar and Salt, 2008). This, we contend, neglects the important question of how demand for business travel, and what it enables (eg: face-to-face, sales, staff management), comes to be ingrained in how business is done.

In this chapter we offer a new perspective on demand for travel by focusing on the rise of global professional firms; specifically global construction and engineering consulting firms. We do this by drawing upon Schatzki's $(2006,2009)$ notion of timespace. Specifically, we explore how demand for business travel arises as a result of the need for the coordination of business through interwoven timespaces. This view is found to offer new insights into the creation of, and ways of thinking about the challenge of reducing demand for business travel. In particular it reveals how forms of corporate organisation have co-evolved with the role of mobility in society. We argue that over time, changes to the interweaving of timespaces have evolved in ways inseparable from the possibilities for and provision of business travel; and in turn this creates a contemporary situation of significant and hard to reduce demand for travel.

We begin by summarising insights and knowledge gaps from an emerging body of work that has traced the reasons for business travel. This is followed with a summary of our 
case study of two UK consulting firms. Schatzki's notion of timespace is then introduced and applied to interpret a contextualised history of how coordination is achieved in professional service firms when procuring and arranging work. We conclude with a wider discussion of the value of our approach for understanding mobility-intensive business practices.

\section{Conceptualising demand for business travel}

Research has identified how business travel facilitates attending meetings (Lyons, 2013) and conferences (Storme et al., 2016); working on global projects (Faulconbridge, 2006); managing corporate subsidiaries and those working in them (Jones, 2007); attending to existing clients (Millar and Salt, 2008) and identifying new ones (Wickham and Vecchi, 2009). Underlying such analyses is recognition of the 'compulsions of proximity' (Urry, 2003), and in particular the continued significance of embodied encounters (Strengers, 2015) in the doing of business. Such concerns speak to the teleo-affective nature of travel. Teleology highlights goals and ends of a particular practice (e.g. attending to existing clients), whilst affectivity highlights a range of emotions that inform the doing, and/or reflect what is acceptable (e.g. social expectation of co-presence when pitching an idea to a new client) (Schatzki, 2005, 2006b, 2013). As a result, the 'need' for travel is most often explained by what it enables, what cannot be achieved at a distance, and what is expected in the corporate world.

Reducing demand for business travel is, however, a widespread ambition. This stems from environmental concerns - how companies might reduce travel and its carbon impactsas well as a desire to reduce the cost of travel and negative effects upon employee wellbeing. Such concerns are part of a long running debate about substitution and the role of, in particular, video conference technologies. To summarise, questions are raised about what the 'bandwidth' of tele- and screen-based encounters cannot facilitate and how technological developments might recreate the affordances of 'being there' (see, for example, Arnfalk and 
Kogg, 2003; Gallié and Guichard, 2005). The main response to such debates has been to emphasise the limitations of substitution, given the way that physically inhabiting the same space brings about opportunism (Storme et al., 2016) and corporeal encounters (Strengers, 2015) that are valued and many do not want to forgo. Hence co-operation (Faulconbridge et al., 2009) and alliance (Haynes, 2010) between travel and technologically-facilitated interactions has been highlighted. Workers and firms, therefore, find themselves in the difficult situation of wanting to reduce travel for a variety of reasons, but being unable to imagine conducting business without mobility (Cohen 2010; Lassen, 2010).

In this chapter we treat the demand for business travel as arising from the ongoing reproduction of bundles of spatially stretched work practices (Shove and Walker, 2014; Thrift, 2008). These practices involve a range of tasks, activities and decisions (henceforth collectively referred to as actions) that are coordinated through the interweaving of timespaces. Demand for business travel, therefore, is suggested here as not simply the product of function, like the need to physically travel to touch and fix a photocopy machine (Orr, 1996). Nor is it the product of conventions around building trust through co-presence (Jones, 2007). These factors undoubtedly encourage travel. However, we argue that the rootcause of demand for travel is the development of forms of corporate organisation that necessitate the interweaving of the timespaces of spatially distributed and temporally dispersed actors so as to coordinate a range of actions. We argue that overtime interweaving has become more complex as forms of organisation have co-evolved with changing ICT and mobility affordances and provision. This implies that demand reduction might arise not from virtual ways of working, but through corporate reorganisation that produces work practices which require the interweaving of the timespaces of less spatially stretched actor constellations, or interweaving not premised on travel. 


\section{The case \& approach}

Our starting point for capturing changes in demand for business travel is to place business practices centre stage (Reckwitz, 2002; Shove et al., 2012). In part we are inspired by Jones (2013: 63) who suggests that business travel itself might be conceived of as a "socio-economic practice that involves individuals or groups moving for the purposes of economic activity". For Jones (2013), the benefit of this focus comes from the three interrelated insights gained from understanding what people do: spatio-temporality is revealed, in terms of business travel's effects on time and space; function becomes clear in terms of economic outcomes; and analytical clarity is gained about when travel is significant and contributes to economic outcomes. This focus suggests understanding how travel correlates with company strategy and spatial work arrangement (Aguiléra, 2008) and helps to achieve business outcomes (Jones, 2013).

We agree with Jones's call to adopt a practice perspective. However, there is one key consideration on which we diverge. In viewing business travel itself as a practice we learn a lot about the affordances of travel, but little about the underlying sources of demand for travel. Suggesting that the need to meet face-to-face is the cause of the demand for travel relies too heavily on a teleo-affective account of co-presence, providing limited insight into why corporate organisation has evolved in a way that makes it reliant on travel-enabled teleoaffectivities. In the engineering and construction business sector, like many business sectors, overcoming spatial constraints has, and continues to be, a central defining feature of recent forms of corporate organisation. This, we contend, is the source of demand for business travel, and hence if the intention is to better understand sources and in turn ways of reducing demand, the work practices associated with contemporary forms of corporate organisation and the way their coordination is achieved through interwoven timespaces should be the focus of a practice perspective. To develop this argument, we draw from a one year case study of how two professional service firms procure and arrange work. 
The two UK-based firms work in the civil engineering and survey consulting business sector. This sector provides design and construction services to a range of public and private clients. The fundamental work of these firms is the application of specialist technical knowledge such as engineering, architecture and planning to the design and construction of a range of waste, transport and energy projects. Essentially, firms procure work from a client (e.g. private/public rail sector), for a project (e.g. construction of new or alteration of existing piece of railway) which then needs to be delivered by a team within the firm. Both of our case study firms have a strong UK presence, but also have a global reach and reputation. The firms were selected by obtaining a list of candidate firms from the Guardian UK 300 (Targetjobs, 2015). Based on rankings of the top 10 civil engineering and consulting firms over the past 5 years, a list of potential firms was identified and access gained to two through existing professional connections.

The limitations and strengths of conducting a case study of a phenomenon are well documented (Bryman, 2008; Yanow \& Schwartz-Shea, 2006). Though lacking in generalisability, case studies can reveal a richer, more nuanced depiction of a phenomenon. The chosen case study is valuable for a number of reasons. First, the firms' global reach allows us to develop new knowledge about the creation, maintenance and suppression of international business travel which is recognised as a particular environmentally damaging and personally demanding form of mobility. Second, compared to finance, IT and mining, the construction and engineering consulting business sector has received significantly less attention by scholars, and thus we offer new insight into demand in a travel-intensive sector (Anable et. al., 2015). Third, our two firms have successfully maintained their global presence through continued firm consolidation and reorganisation, most recently in light of the Global Financial Crises. This provides a window on how the evolution of corporate organisation affects demand for travel. 
Twenty one-to-one interviews, based on a semi-structured interview protocol, were conducted, transcribed and then coded and analysed through QSR NVivo software. After an initial introduction into each case study firm by professional contacts, participants were identified by snowballing (i.e. feedback from interview participants) and criteria-specific identification (i.e. from review of corporate documents) (Bryman, 2008; Neuman, 2011). Interviews generally lasted one hour, beginning with participants describing their day-to-day tasks, and then shifting to discussions of procuring and arranging work. Rather than ask why virtually-mediated ways of working don't substitute for physical ways of working or why workers travel, we sought to draw out how demand for travel arises from coordinating actions involved in procuring and arranging work in a globalised business world.

\section{Business practices and travel demand}

The globalisation of our two case study firms, like in other studies of business travel, is central to the story of the 'need' for travel. The speeding up of travel has extended the spatial reach of corporations and enabled their globalisation (Dicken, 2011). This results in what Harvey (1999) refers to as 'time-space compression', where markets stretched across space are serviced largely through mobility. Time-space compression thus enables and encourages the creation of business practices which create and stabilise demand for business

travel. Schatzki $(2009,2012,2013)$, through the concept of timespace, offers a valuable way of understanding the temporal and spatial features of the business practices that make up our case study firms and which are fundamental to demand for travel.

For Schatzki (2013), timespace is a fundamental influence on action. It is composed of both objective and relational dimensions. ${ }^{\text {i }}$ Objective time relates to measurable units, such as the minutes and hours of clock time, whilst objective space relates to identifiable locations, in our case for example an office (in a city with a GPS location). Relational time, which can be referred to as temporality, is the result of past, present and future orientations which 
influence action (see Hydle, 2015). Relational space, or spatiality, “embraces arrays of places and paths anchored in entities, where a place is a place to perform some action and a path is a way among places" (Schatzki, 2012: 19). It is the amalgamation of the locations and paths between them that together constitute the spatial realm of the actors in question. In timespace, objective and relational space and time are viewed as "inherently related constituted dimensions of action" (Schatzki, 2013: xi).

Schatzki draws attention to how coordinated action is only possible when timespaces are interwoven (Schatzki, 2010: 87). Interweaving relates to the way "lives hang together" (Schatzki, 2013: 66) as a result of forms of interdependence between different actors and their practices. Timespace can be interwoven when action occurs: same place, same time; different place, same time; different place, different time; or same place, different time. The key is that the actors are interdependent, and in turn coordination results. This means actions "combine to achieve a result that someone intends to be achieved" (Schatzki, 2013: 69). Schatzki (2013: 66-67) argues that interweaving and thus coordination occurs in four ways: interpersonal structuring (shared ends, means, emotions), chains of action (each actor following/reaction to another), intentional directedness (when an actor is focussed on the actions and emotions of another), and the medium of settings (connections between actors that give them shared lives, events and stimuli). As we discus more fully later, the need for interwoven timespaces generated by contemporary forms of corporate organisation means chains of action and intentional directedness are key in the firms in our case study, this creating demand for travel.

Specifically, whilst coordination in our case study firms, like in all forms of economic organisation, "rests on common, shared and orchestrated timespaces", particularly important are common and shared timespaces because "Orchestration, by itself, is unable to ensure coordination" (Schatzki, 2013: 71). Orchestration is limiting because it involves actors 
pursuing their own aims, despite these aims ultimately being interdependent with the aims of others (Schatzki, 2009: 42). For our case study firms this risks undermining global corporate strategies and the desire to provide global 'one stop shop' services to clients. Common timespaces are more productive because they are characterised by "enjoined" actors who share "ends, purposes, motivations, places, paths" (Schatzki, 2012: 20). I.e., actors work in an enjoined way to deliver global corporate strategy and service. Shared timespaces are also characterised by "the same ends or motivations or at the same places and paths", but actors are not enjoined and as such co-exist rather than collaborate (Schatzki, 2012: 20). Demand for business travel arises from the need to create interwoven shared and ideally common timespaces that encompass spatially stretched actors procuring, producing and delivering services. Travel is also related to the desire for harmonised timespaces in which "the actions of people who are simultaneously proceeding in the same or connected settings smoothly fit together through the contingent adjustment of each person's behaviour to what others are doing" (Schatzki, 2009: 43-44). Harmonised timespaces avoid conflict (conflicting timespaces occurring when different actors jostle rather than align their actions) and, as we discuss, are the panacea that our case study firms strive to develop.

The interweaving of common, shared and harmonised timespaces, which enable firms to procure and arrange work, "prescribe and circumscribe spaces, times, sequences and formal relations" that give character, rhythm and form to everyday life in organisations (Schatzki, 2013: 141). As far as our concern with business travel, this means considering how the need for the coordination of actions accomplished through different interwoven timespaces creates demand for business travel. With this goal in mind, we begin by tracing important changes in the sector over the past century. Drawing from secondary sources (pre2000), the contextualised historical account provides the backdrop for understanding the types of timespaces interwoven in our two case study firms post-2000 and the implications 
for the demand for travel. Though many business practices involve the interweaving of timespaces, given our research focus, our discussion is confined to coordinated actions involved in the procuring and arranging of work.

\section{Historical changes to the interweaving of timespaces}

The market for construction and engineering consulting services is related to the growth of industries and construction, the ebbs and flows in public and private spending on infrastructure and manufacturing, and the deskilling within local and national government in the move towards a prevalence of consulting (Kakabadse and Kakabadse, 2001). Historically, in the case of our two study firms, procuring and arranging work was focused at the regional level, as defined by a particular firm office. For example, in procuring work, profit and loss accounts for the firms ensured project teams were drawn from offices within a particular national region, and often only one office. This arrangement, encouraged and facilitated by common and even harmonised interwoven timespaces, ensured that the coordination benefits that ensue were relatively easy to achieve. Interpersonal structuring, made possible by permanent or easily facilitated co-presence, was the dominant way of interweaving timespaces. Consultancies conducted their work within one office and/or on the project site, or made occasional physical trips to the client based on the expectation of personal interaction between the provider and the client (Baark, 1998). Demand for travel to interweave timespaces, whilst not absent, was therefore low.

The relatively constrained objective spatial and temporal qualities of the procurement and arrangement of work came to be unsettled by a number of events; notable being globalisation and structural changes to the engineering consulting industry, computer software and networks, international regulatory reforms and airline de-regulation. These changes led to a turn towards proactive global 'market seeking' strategies. Engineering consultancies began to redefine "themselves in terms of their entrepreneurial endeavours" 
(Coyne et al., 1996: 749) and opening new offices or divisions abroad. Establishing an office was initially driven by the 'follow the client' logic. Opening offices outside the UK continued to be staffed with consultants able to deliver local projects for the client in question; thus continuing to rely on timespaces interweaved through interpersonal structuring. However, a number of changes quickly undermined this state of affairs.

In the 1980s, personal computer workstations became ubiquitous and gradually indispensable in the operation of engineering consultancy firms. Initially, the financial costs of linking computer workstations with Computer Aided Design (CAD) software and other emerging telecommunication networks was financially prohibitive except for large firms. These telecommunication systems eventually spread throughout the consulting sector, becoming taken for granted and encouraging the rise global divisions 24 hour working patterns (Tombesi, 2001). Consequently, whilst historically project team members (designers, engineers, architects) would meet daily around the drafting table to accomplish project outcomes, by the 2000s this had changed significantly. Although drawings remain a critical tool for shared interpretation, the introduction of CAD and ICT into the arrangement of work resulted in not only fewer routine technical workers (Baark, 1998; Coyne et al., 1996) but also a greater tendency to work in teams that share documents electronically. Such changes began to blur the boundaries of working time and location (Vendramin et al., 2000) as project teams became spatially stretched and temporally dispersed—something new accounting systems and performance assessments further encouraged (Buch and Anderson, 2015). Thus, both client-facing and internal-firm features of our case study firms began to emphasis communication skills and production rhythms conducive to coordinating actions where objective space was stretched and time dispersed (different place same time; different place different time). This emphasis alludes to how chains of action can re-bundle various business practices (see Schatzki, 2013: 76-78). Chains of actions described below which 
constitute how coordinated actions involved in the procuring and arranging of work occur today (in the future), linked through past chains of action discussed here, came to encourage the interweaving of timespaces where objective space and time were less constraining features of coordinating action.

Concurrently, the de-regulation of the airline industry, beginning in the 1970s but having noticeable effects in the 1990s and later, lessened the financial burden of flying experts around the country or the world. This change does reflect a simple supply creates demand scenario. Yet, de-regulation also further normalised time-space compression and the wider global trend towards globalised work. For example, in our two case study firms, ease of flying strengthened the geographical reach of each firm. In turn, firm strategies began to target new business opportunities both within the UK and abroad. Firm strategies began to stipulate and normalise the procuring of work based on specific projects and skill sets within the wider firm, not within any one particular office. This change rendered travel-enabled work practices not only cheaper but also indispensable. New firm procurement strategies, therefore, supported and encouraged a re-organisation of teams and offices, as senior staff and project managers began to observe that a single office no longer needed to contain a full array of professional skill sets, as potential workers could be drawn from different offices.

Spatially stretched and temporally dispersed actions had significant implications for the interweaving of timespaces. The emergence of orchestrated timespaces in which different aims are pursued (e.g. two offices chasing very different types of work) despite interdependence (all offices needing to procure similar work that can be shared globally) risked undermining coordination. No-longer was interweaving achieved solely by interpersonal structuring. Chains of action, brought about by changes in technology and airline deregulation, ensured that work passed between offices brought a constellation of actors into interdependence. Further, new intentional directedness emerged as actors in 
different places but doing similar work came to be directed towards one-another, for instance through membership of the same global practice group.

In summary, over a couple of decades, timespaces for the engineering consulting business sector, as illustrated by our two case study firms, shifted from predominantly common timespaces with local characteristics (same place, same time; same place, different time), towards spatially stretched orchestrated timespaces (different place, same time; different place, different time). This imples that overtime, to ensure coordination of actions related to procuring and arranging of work, more elaborate corporate tactics became necessary for interweaving timespaces, the rise in demand for travel being intimately related to this adoption of new tactics.

\section{How timespaces are interwoven today}

Today, each of our two case study firms have grown in size and broadened their capabilities so that they are capable of acting as a 'one stop shop' (UNESCO 2010; Buch and Anderson, 2015). This began in the late 1980s as the sector moved towards designbuild coalitions as software and communication innovations called for the increased integration of diverse disciplinary knowledge and skills. Specialising in large projects such as airport construction, for example, allows a firm to sell and deploy their full array of specific skills sets, from geotechnical, seismic and acoustics, to civil and structural engineering and architecture, irrespective of objective space and time constraints which are now routinely overcome through various changes discussed above

Whereas our two case study firms were historically organised regionally within countries, today, project teams are structured globally by discipline, often irrespective of office location. In addition, firm profit and loss accounts are no longer based on office, but on disciplines and professional expertise. Further, intra-net capabilities in our two firms provide employees with databases to share ideas for procuring work, client information, bid 
information, etc. These arrangements involve virtual ways of working, and thus a mix of very complex common, shared and orchestrated timespaces suitable to overcome the constraints of objective time and space.

As Schatzki’s (2013: 52) perspective reminds us, the timespaces of any one actor for any given practice is "partly common, partly shared, and partly personal". In the case of our firms, "organisations circumscribe the shared dimension of their participants' timespaces because teleoaffective structures comprise acceptable futures in addition to enjoined ones" (Schatzki, 2013: 53). The importance of acceptable futures can be observed in how, today, practice groups and teams operate in our case study firms. All individuals are a member of global practice group, and are expected to contribute to the strengthening of that group's competitiveness. Meanwhile, work is organised in teams which are staffed by the most qualified individual regardless of location, subject to availability at the required time. In both, there is a risk of orchestrated timespaces undermining the strategic priorities of the firm, given that in these, coordination is difficult to achieve. Common timespaces and enjoined actors, and ideally harmonized timespaces in which there is "seamless interlocking" (Schatzki, 2013: 88), are needed. As such, both firms invest in developing and nurturing trust and respect and a sense of shared agenda, as both are central to ensuring good professional relationships and ultimately movement towards enjoinment and harmony.

The complex arrangements required to ensure coordination in our two firms today can be illustrated through the following examples. A CEO recently wrote to all staff to indicate that being more geographically mobile was an increasingly important part of business-asusual for the firm. From our perspective, the letter further embedded existing conventions and norms around working for a global-engineering consulting firm. Specifically, the letter underscores the centrality of travel in the production of shared and harmonized timespaces associated with procuring and arranging work. For existing staff there was a degree of 
reluctance (due to family arrangements, for example) but nonetheless this was seen as part of new terms and conditions for graduate jobs and acknowledged as a way of getting on in the firm. Indeed, Key Performance Indicators at senior management level included being visible, mobile and geographically agile. This reflects an acceptance that whilst virtual communications are acceptable in some cases (principally non-client communication), and increasingly a part of some working practices (e.g. CAD production in India), travel and the creation of common and harmonised timespaces that it allows is unavoidable. Hence demand for business travel in our case firms is a result of its critical role in interweaving timespaces and ensuring coordination when work is procured and completed.

\section{Conclusion}

This chapter has provided an account of how demand for business travel is intrinsically related to how business actions are organised spatially and temporally. Schatzki's $(2009,2012,2013)$ notion of timespace highlights how our case study firms constitute 'a bundle of practices and material arrangements' $(2005,2006 a)$. Such features did not emerge overnight, but reflect several decades of changes which have occurred within the wider professional services sector. Overtime, the interweaving of timespaces, which is essential to coordinate actions related to procuring and arranging of work, has become more elaborate as tasks, activities and decisions have been stretched across different places and dispersed in time. Simply said, procuring work back in 1920 is different to how work is procured today. This history illustrates the broad, fluid and historical preconditions of the sites as well as the material arrangements that prefigure how our firms bid for and arrange work. With respect to demand for travel, changes to the interweaving of timespaces mean that travel, as in broader society, has become more inscribed into the profession of engineering consultancy and in the firms in our case study. 
As organisations help to circumscribe the context for coordinating actions and thus help to interweave timespaces, the concept of timespaces offers scholars an alternative way to think about how past organisation practices shape current work practices, how work practices continue to evolve, and how work practices might be steered to promote temporalities and spatialities that reduce demand for travel. As other chapters in this book also reflect upon, drawing attention to the spatialities and temporalities of energy practices help to make sense of the historical, current and future variability and transformations of energy demand. Important spatial and temporal features which demand business travel can be observed in a variety of ways. For instance, changes in firm strategies and organisational restructuring, affordances brought about through ICT (e.g. telecommunications, CAD, inter/intra-net, servers, virtual communication) and mobility (e.g. low cost airlines and regional airports, travel management companies, company cars, high speed trains) helped to spatially stretch and temporally disperse actions. Thus, objective space and time came to be less and less a constraining. This relates to changes in how 'lives hang together' and interwoven timespaces are developed (Schatzki, 2013). Given the tendency for spatial stretching (actions at different places at the same or different times) interpersonal structuring of timespaces is now more difficult and does not happen organically. As a result, interweaving of timespaces through chains of action and intentional directedness becomes important, but both require greater seeding and effort if coordination is to be ensured. As a result, over time, our two firms have evolved to embed mobility in how each bids for and arranges work. Hence, neither firm could not operate without the travel that for environmental and other concerns they may wish to reduce.

Our findings and focus on changes in the interweaving of timespaces strongly suggests that questions about if and how technology (video conference in particular) might substitute for travel need to be complemented by perspectives on what creates demand for 
travel in the first place. If, as research suggests (Strengers, 2015; Hayes, 2010), technology cannot substitute for the well-known affordances of corporeal co-presence, then understanding how demand for travel is made is essential so that multiple ways of unmaking it become possible. Space-time compression brought about by changes in technology is central to understanding today's global economy in which our firms operate. However, Schatzki (2013: 87) notes that transformation and redesign of interwoven timespaces was also central to space-time compression, "changes in social life require changes in temporalspatiality." As such, to reduce travel means considering different ways to interweave timespaces.

An obvious answer is to reduce the spatial stretching and temporal dispersion that has meant travel is needed to allow chains of action and intentional directedness, and in turn coordination. Yet, even in the current moment when there seems to be growing scepticism as far as globalization is concerned, a return to localised business is hard to imagine. The strategic locating of different elements of the bidding and work delivery process might offer one compromise (Jones, 2013). Given the insights gained into the need for travel to interweave timespaces and ensure coordination, it might be possible to identify the individuals and practices that require most travel and to co-locate these whilst maintaining global operations and clients. Alternatively, the question of technological substitution could be reimagined. Instead of asking how technology can reproduce the affordances of embodied encounter, research might ask how the interweaving of timespaces can be achieved via technology. This is a subtly different question because it highlights the possibility that coordination achieved as a result of chains of action and intentional directedness might be enabled by technology. This enabling might be associated with technologically facilitated following/reacting to others (for chains of action) and/or focus on the actions/emotions of others (intentional directedness) that is not simply about reproducing meetings via video- 
conferencing or alike. For instance, might technology generate forms of continual connection in ways that allow the development an awareness of and ability to respond to what others do in different times and places? This might involve forms of visualisation that already exist in project management and intranet tools, but in enhanced. There is much to work through in relation to such an idea, but the key point is that perhaps we need to imagine new ways of interweaving timespaces that is not limited only to travel or the technological substitution of meetings. Technologically interweaved timespaces might, then, be a productive agenda for research.

\section{References}

Aguiléra, A (2008) Business travel and mobile workers. Transportation Research Part A: Policy and Practice 42: 1109-1116.

Anable J Darnton A Pangbourne K Lane B Banks N and Henry N (2015) Evidence Base Review of Business Travel Behaviour to Inform Development of a Segmentation of Businesses: Main Report. Report for the Department for Transport. March 2015.

Arnfalk P and Kogg B (2003) Service Transformation - Managing a Shift from Business Travel to Virtual Meetings. Journal of Cleaner Production 11: 859-872.

Baark E (1998) Engineering Consultancy: An Assessment of IT-enabled International Delivery of Services. Working Paper in the Social Sciences, No. 40, Division of Social Science, The Hong Kong University of Science and Technology.

Bryman A (2008) Social research methods, New York: Oxford University Press.

Buch A and Andersen V (2015) Team and project work in engineering practices. Nordic Journal of Working Life Studies 5: 27-46.

Cohen MJ (2010) Destination inknown: persuing sustainable mobility in the face of rival societal aspirations, Research Policy 39: 459-470.

Coyne RD Sudweeks F and Haynes D (1996) Who needs the Internet? computer-mediated communication in design firms. Environment and Planning B: Planning and Design 23: 749770 .

Davidson R Cope B (2003) Business travel, Pearson: Harlow.

Dicken P (2011) Global shift: mapping the changing contours of the world, London: Sage Publications.

Faulconbridge JR Beaverstock JV Derudder B and Witlox F (2009) Corporate ecologies of business travel in professional service firms: working towards a research agenda. European Urban and Regional Studies 16: 295-308. 
Faulconbridge JR (2006) Stretching tacit knowledge beyond a local fix? global spaces of learning in advertising professional service firms. Journal of Economic Geography 6: $517-$ 540 .

Gallié EP and Guichard R (2005) Do collaboratories mean the end of face-to-face interactions? An evidence from the ISEE project. Economics of Innovation and New Technology 14: 517-532.

Haynes P (2010) Information and communication technology and international business travel: mobility allies? Mobilities 5: 547-564.

Harvey D (1999) The condition of postmodernity: an enquiry into the origins of cultural change, Blackwell: Cambridge.

Haynes P (2010) Information and Communication Technology and international business travel: mobility allies? Mobilities 5: 547-564.

Hydle K (2015) Temporal and spatial dimensions of strategizing. Organization Studies 36: 643-663.

Jones A (2007) More than 'managing across borders"? the complex role of face-to-face interaction in globalizing law firms. Journal of Economic Geography 7: 223-246.

Jones A (2013) Conceptualising business mobilities: towards an analytical framework. Research in Transportation Business \& Management 9: 58-66.

Kakabadse A and Kakabadse N (2001) Outsourcing in the public services: a comparative analysis of practice, capability and impact. Public Administration and development 21: 401413.

Lassen C (2010) Environmentalist in business class: an analysis of air travel and environmental attitude. Transport Reviews 30: 733-751.

Lyons G (2013) Business travel - the social practices surrounding meetings. Research in Transportation Business \& Management 9: 50-57.

Millar J and Salt J (2008) Portfolios of mobility: the movement of expertise in transnational corporations in two sectors-aerospace and extractive industries. Global Networks 8: 25-50.

Neuman WL (2011) Social research methods: qualitative and quantitative approaches, Boston: Allyn \& Bacon.

Reckwitz A (2002) Toward a theory of social practices: a development in culturalist theorizing. European Journal of Social Theory 5: 243-263.

Salt J and Wood P (2012) Recession and international corporate mobility. Global Networks 12: 425-543.

Schatzki TR (2005) Peripheral Vision: The sites of organizations. Organization Studies 26: 465-484.

Schatzki TR (2006a) On organizations as they happen. Organization Studies 27: 1863-1873.

Schatzki TR (2006b) The time of activity. Continental Philosophy Review 39: 155-182. 
Schatzki TR (2009) Timespace and the Organization of Social Life In: Shove E Trentmann F and Wilk R (Eds) Time, consumption and everyday practice: practice, materiality and culture. Oxford: Berg, 35-48.

Schatzki TR (2012) A primer on practices In: Higgs J Barnett R Billett S Hutchings M and Trede F (Eds) Practice-based education: perspectives and strategies. Sense: Rotterdam, 1326.

Schatzki TR (2013) The timespace of human activity: on performance, society, and history as indeterminate teleological events, Lexington Books: Lanham.

Sheller M and Urry J (2000) The city and the car. International Journal of Urban and Regional Research 24: 737-757.

Shove E Pantzar M and Watson M (2012) The Dynamics of Social Practice, London: Sage Publications.

Shove E and Walker G (2014) What is energy for? social practice and energy demand. Theory, Culture \& Society 31: 41-58.

Storme T Faulconbridge JR Beaverstock JV Derudder B and Witlox F (2016) Mobility and Professional Networks in Academia: An Exploration of the Obligations of Presence, Mobilities, http://dx.doi.org/10.1080/17450101.2015.1116884

Strengers Y (2015) Meeting in the global workplace: air travel, telepresence and the body. Mobilities 4: 592-608.

Targetjobs (2015) http://www.Targetjobs.co.uk [last accessed 12/10/15]

Thrift N (2008) Non-representational theory: space, politics, affect, Routledge: Oxon.

Tombesi P (2001) A true south for design? The new international division of labour ni architecture. Architectural Research Quarterly 5: 171-180.

UNESCO (2010) Engineering: Issues, Challenges and Opportunities for Development. United Nations Educational, Scientific and Cultural Organisation, Paris.

Urry J (2003) Social networks, travel and talk. British Journal of Sociology 54: 155-175.

Urry J (2012) Do mobile lives have a future? Tijdschrift voor Economische en Sociale Geograpfie 103: 566-576.

Vendramin P Valenduc G Rolland I Richardson R Gillespie A et al. (2000) Flexible work practices and communication technology (FLEXCOT project). 164 pages. Accessed 7/7/16 at: http://hdl.handle.net/2078.1/129542

Wickham J and Vecchi A (2009) The importance of business travel for industrial clusters making sense of nomadic workers. Geografiska Annaler: Series B, Human Geography 91: 245-255.

Yanow D and Schwartz-Shea P (Eds) (2006) Interpretation and Method: Empirical Research Methods and the Interpretive Turn, M.E. Sharpe: New York. 
'Though Schatzki uses the term activity timespace to differentiate it from Heidegger's notion of timespace which is also a crucial feature of human life, our use of timespace accords with the concept as developed by Schatzki. 